\title{
The effects of long-term administration of guarana on the cognition of normal, elderly volunteers
}

\author{
Brazilian Information Center on Psychotropic Drugs of the Department of \\ Psychobiology at the Federal University of São Paulo - São Paulo, Brazil
}

Paulinia cupana (guarana) is a Brazilian plant given great prestige in popular medicine, for example as being a potent stimulator of brain functions. The authors assessed the effects of the long-term administration of guarana on the cognition of normal, elderly volunteers. Forty-five volunteers were studied, with a random distribution in three experimental groups: placebo ( $n=15$ ), caffeine $(n=15)$, and guarana $(n=15)$, in a double-blind study. There were no significant cognitive alterations in these volunteers.

UNITERMS: Paulinia cupana (guarana). Cognition. Medicinal plants.

\section{INTRODUCTION}

$\mathrm{T}$ The concept of adaptive or resistant drugs has arisen in the past 20-30 years thanks to extensive research done by Soviet, Japanese and Korean scientists on several plants, especially those from the Araliaceae family. Although folkloric use of these plants has always spurred curiosity, there have been, in general, few scientific studies on these plants. In fact, it has been difficult to observe any immediate effect of these plants in relation to all the alleged therapeutic effects that have been reported by popular medicine ${ }^{11 .}{ }^{12}$. It was only possible to verify their typical effects and isolate their active ingredients ${ }^{2}$

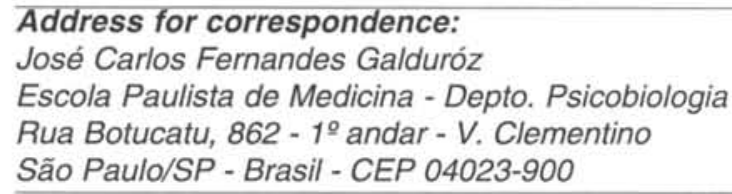

when investigations stopped searching for short-term effects in normal animals, and demonstrated the plants' protection against aggressive agents through long-term use.

Of ten adaptive plants studied in the former Soviet Union, five have already been officially approved for therapeutic use ${ }^{2}$ : Panax ginseng, Aralia elata, Aralia cordata, Acanthopanax senticocus (used for astronaut preparation) and Oplopanax elatus.

In Brazil, our scientific community has devoted little effort to investigating our vast flora for adaptive plants. Therefore, it is not possible to find scientific studies relevant to this matter. However, in Brazilian popular medicine, several plants are used with the same purpose as other folk medicine found in China and other countries. Guarana (Paulinia cupana) and the Pfaffia paniculata are good examples.

Guarana is attributed with powerful preventive and curative actions (all without scientific proof) and, among these, we can cite some of its indications: neuralgia, migraine, arteriosclerosis, menstrual pain, weight loss, 
renal activation, bad digestion, heart and brain stimulation, and others ${ }^{19}$.

Anthropologist A. HENMAN, in his 1986 study of guarana ${ }^{16}$, describes the use of this plant by the SatereMaue Indians who live in the Amazon, emphasizing its use as a liquid preparation which is diluted and taken several times during the day on a long-term basis. He also reports that guarana has been used by these Indians for centuries as a stimulant, headache medicine, and for relief of cramps, etc.

In relation to its botanical classification, PIO CORREA $^{21}$ as well as HENMAN ${ }^{16}$, describe guarana as being from the Sapiendaceae family, with two subspecies: Paulinia cupana var sorbilis and Paulinia cupana var typica. Chemically guarana is characterized by its highgrade caffeine, with a smaller quantity of theophylline and theobomine. It is known that these substances do not have pharmacological actions that can explain all the therapeutic effects popularly attributed to guarana. In fact, the central stimulating effect of caffeine cannot explain the majority of the ${ }^{3}$. On the other hand, a presence of a high concentration of tannin in guarana has been described as 4-6 percent, according to HENMAN ${ }^{16}$.

The following study considers the effect of the longterm use of guarana on the cognition of normal, elderly volunteers.

\section{PATIENTS AND METHODS}

Forty-five volunteers fit the following selection criteria:

- Over 60 years-old (several studies have demonstrated that, after the age of 50-55, a decline in cognitive functions begins, which does not mean any pathologic manifestation ${ }^{6.15}$;

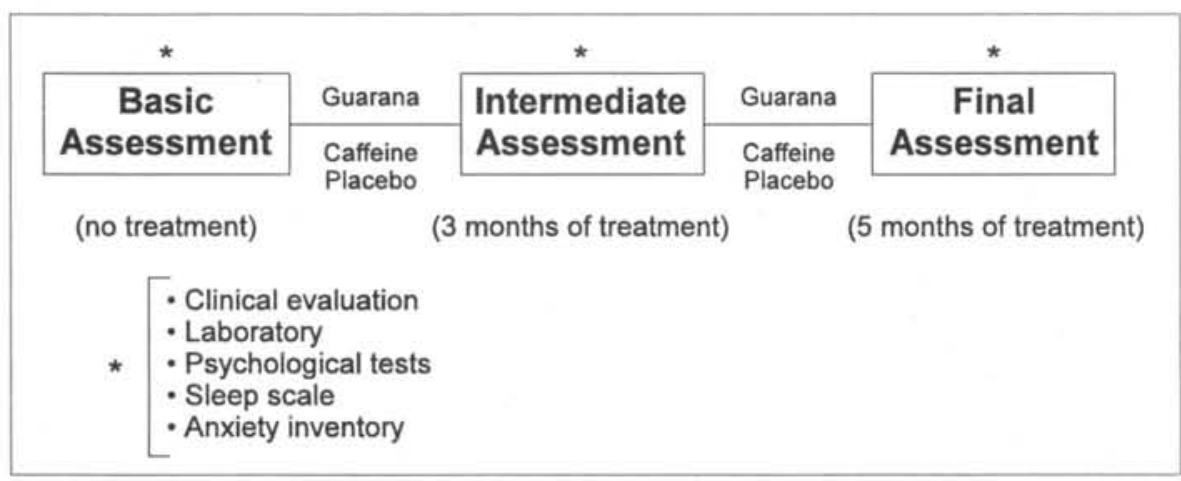

Figure 1 - The study procedure.
- At least a sixth grade education (to avoid bias in cognitive assessment);

- Free of medications;

- No significant physical or mental disturbances.

The project was approved by the Ethics Committee of the Federal University of São Paulo in Anima Nobili. All volunteers signed a Term of Agreement to participate.

\section{EXPERIMENTAL GROUPS}

Three experimental groups were formed, each with 15 volunteers:

\section{GROUP I - PLACEBO}

GROUP II - CAFFEINE, in quantities equivalent to doses of administered guarana. The purpose of this group was to assess the different cognitive effects of guarana and caffeine, if any.

\section{GROUP III - GUARANA}

The sample of guarana used was analyzed by EMBRAPA (Brazilian Agropecuarian Research Company) and had the following components:

Moisture: $8.80 \%$

Ash: $1.51 \%$

Caffeine: $2.10 \%$

Tannin: $16 \%$

The volunteers in each experimental group took two capsules a day (one in the morning, one in the afternoon) for 150 days of the study. Each capsule contained $500 \mathrm{mg}$ of powdered guarana; the capsules of caffeine contained $12.5 \mathrm{mg}$. The placebo was brown sugar ( $500 \mathrm{mg} /$ capsule) .

The doses of 1 gram of guarana per day was decided upon after studying the recommendations of laboratories that sold the product, and a previous study done by this department ${ }^{13}$.

All capsules were identical since this was a doubleblind study, and volunteers were randomly divided into one of the three experimental groups.

\section{Evaluation instruments}

\section{Cognitive evaluation}

The Mini-Mental State ${ }^{10}$ was used as screening for dementia with a cut-off score of 23 points. Among neuropsychological assays, we used Digital Span ${ }^{24}$ to assess immediate memory; Free Recall for recent 
memory'; Digital Symbol to evaluate psychomotor activity and concentration ${ }^{8,14}$; Cancellation tests to verify vigilance and attention ${ }^{7}$; and, finally, the Mosaic test for visual and spacial organization $^{18}$.

The Raven - Progressive Matrices (Advanced Scale) was used. It is indicated to assess general abilities, having shown sensitivity to detect reasoning and visual perception damage $^{5}$.

\section{Sleep assessment scale}

To verify possible drug interferences in sleep during treatment ${ }^{4}$.

\section{Anxiety assessment scale}

We used the State-Trait Anxiety Inventory ${ }^{22}$.

\section{Experimental Procedure}

Each volunteer was submitted to a clinical evaluation (physical and laboratory exams) followed by the MiniMental State exam and neuropsychological tests to determine the basal cognitive state. We also applied the Sleep Scale and the Anxiety Inventory.

The selected volunteers initiated the intake of one of the three substances with initial clinical follow-up every week, and then every month (to receive more capsules, thus providing not only the necessary clinical care, but also assuring us that the substances were being used regularly). In the third and fifth month after beginning treatment, the complete evaluation of the basis phase was again repeated (Fig.1).

\section{STATISTICAL ANALYSIS}

Data was analysed using non-parametria tests. For the analysis of dependent samples, we used the Friedman test and, for independent samples, we used the Kruskal Wallis test. The significance level was 5 percent.

The study was developed at the Center of Clinical Research of the Department of Psychobiology at the Federal University of São Paulo from January to September 1992.

\section{RESULTS}

These are the following social and demographic characteristics of the 45 subjects: mean age was $65^{(6), 76}$; 20 were male ( 44 percent); 39 married, 5 bachelors, and 1 widower; 25 volunteers had finished high school, 15 had finished primary school and 5 had graduated from university .

Table 1

Immediate (Digit Span) and recent (Free Recall) memory assessment of the $\mathbf{4 5}$ volunteers in the three phases of the study

(results are average score and standard deviation)

\begin{tabular}{llccc}
\hline $\begin{array}{c}\text { Cognitive } \\
\text { tests }\end{array}$ & \multicolumn{4}{c}{ Phases of treatment } \\
\cline { 2 - 5 } Digit Span & Groups & Initial & Interm. & Final \\
\hline & Placebo & $11.4 \pm 2$ & $12.1 \pm 1$ & $12.1 \pm 2$ \\
& Caffeine & $11.4 \pm 2$ & $12.5 \pm 2$ & $12.6 \pm 2$ \\
& Guarana & $10.3 \pm 2$ & $11.8 \pm 1$ & $11.7 \pm 1$ \\
\hline \multicolumn{5}{c}{ Maximum score: 18} \\
Free Recall Caffeine & $14.4 \pm 3$ & $14.4 \pm 2$ & $14.4 \pm 3$ \\
& Guacebo & $14.6 \pm 4$ & $13.9 \pm 4$ & $14.5 \pm 3$ \\
& $13.7 \pm 2$ & $12.8 \pm 3$ & $13.4 \pm 4$ \\
\hline \multicolumn{4}{c}{ Maximum score: 27}
\end{tabular}

Table 1 shows the results of two cognitive tests used for memory assessment. There were no significant differences.

Table 2

Assessment of Psychomotor Performance (Digit Symbol), Attention (Cancellation Test) and Visual Spacial Organization (Mosaic)

(results are average score and standard deviation)

\begin{tabular}{lcccc}
\hline \multirow{2}{*}{$\begin{array}{c}\text { Cognitive } \\
\text { tests }\end{array}$} & \multicolumn{4}{c}{ Phases of treatment } \\
\cline { 2 - 5 } & Groups & Initial & Interm. & Final \\
\hline \multirow{3}{*}{ Digit Symbol } & Placebo & $34.6 \pm 7$ & $36.6 \pm 8$ & $40.8 \pm 8^{*}$ \\
& Caffeine & $31.7 \pm 11$ & $37.5 \pm 10$ & $39.0 \pm 12^{*}$ \\
& Guarana & $35.8 \pm 11$ & $40.0 \pm 12$ & $42.6 \pm 12$ \\
\hline
\end{tabular}

Maximum score: 67

\begin{tabular}{ccccc}
\hline & Placebo & $40.9 \pm 10$ & $40.6 \pm 7$ & $42.9 \pm 7$ \\
Cancellation & Caffeine & $40.2 \pm 7$ & $42.7 \pm 6$ & $42.9 \pm 7$ \\
& Guarana & $42.0 \pm 6$ & $44.3 \pm 6$ & $44.2 \pm 7$ \\
\hline
\end{tabular}

Maximum score: 112

\begin{tabular}{ccccc}
\hline & Placebo & $32.2 \pm 11$ & $34.9 \pm 10$ & $37.2 \pm 9$ \\
Mosaic & Caffeine & $23.8 \pm 12$ & $30.0 \pm 13$ & $30.3 \pm 15$ \\
& Guarana & $35.9 \pm 9$ & $41.0 \pm 9$ & $42.4 \pm 7^{*}$ \\
\hline \multicolumn{4}{c}{ Maximum score: 50}
\end{tabular}

* $p<0.05$ in relation to initial assessment (Friedman test for dependent samples) 
Table 2 shows that the volunteers presented an improvement in the Digit Symbol test when the final and initial assessment were compared, although there were no differences between the three groups (Placebo, Caffeine and Guarana). In the results of the Mosaic test, the guarana group showed significant improvement, but it is important to note that the initial results of this group were already higher in comparison to the other two groups, although not significantly.

Finally, Table 3 shows data in relation to the volunteers' levels of anxiety measured by the Anxiety Inventory and the detection of affected reasoning (Progressive Matrices - Raven). There were no significant alterations.

One patient, under placebo, complained of persistent insomnia during the first week of the experiment, with no improvement after administration of only 1 capsule/day. She only recovered her sleep after interruption of the treatment. There were no other qualitative or quantitative alterations in volunteers' sleep.

Four participants complained of "burning in the stomach"; three were taking guarana and one was taking caffeine. This was improved by decreasing the doses to $500 \mathrm{mg} /$ day and the intake of capsules only after meals. One volunteer who was taking guarana had to interrupt treatment due to tachycardia that was clinically confirmed.

Some curious facts were reported by the volunteers. One woman said that the treatment was "rejuvenating" and "bringing back her joy for life"; she was under placebo. Another said repeatedly that his memory had improved,

Table 3

Anxiety level state trait measured by anxiety inventory and reasoning assessment (Raven) of the $\mathbf{4 5}$ volunteers (results are average score and standard deviation)

\begin{tabular}{cccccc}
\hline Assessment & \multicolumn{3}{c}{ Phases of treatment } & & \\
\cline { 3 - 6 } State & Groups & Initial & Interm. & Final & Scores \\
\hline \multirow{6}{*}{ Trait } & Placebo & $39.4 \pm 9$ & $38.4 \pm 8$ & $36.3 \pm 8$ & $<30$ \\
& Caffeine & $35.8 \pm 10$ & $33.8 \pm 13$ & $31.5 \pm 9$ & $\begin{array}{c}31-40 \\
\text { medium-low }\end{array}$ \\
& Guarana & $33.0 \pm 6$ & $32.8 \pm 4$ & $32.8 \pm 5$ & $\begin{array}{c}41-50 \\
\text { medium-high }\end{array}$ \\
& Clacebo & $38.8 \pm 9$ & - & $37.0 \pm 8$ & $>50$ \\
\multirow{5}{*}{ Raven } & Guarana & $38.3 \pm 8$ & - & $40.2 \pm 5$ & \\
& Clacebo & $6.1 \pm 2$ & - & $6.8 \pm 2$ & Maximum \\
& Caffeine & $5.2 \pm 2$ & - & $6.1 \pm 3$ & score: 12 \\
& Guarana & $5.7 \pm 1$ & - & $6.6 \pm 1$ & \\
\hline
\end{tabular}

which was not confirmed by the tests; he was under caffeine. Nobody reported a rise in libido or improved sexual performance (through spontaneous or stimulated questionnaires).

Laboratory exams remained stable throughout the study and during extended control for two months afterwards.

It is important to emphasize the great interest and work demonstrated by all volunteers, not only in helping with the study, but in also in maintaning the hope of finding a solution for the memory loss that had brought them to our hospital. The withdrawal of two volunteers (one due to insomnia and another due to tachycardia) was a decision made more by the researcher than by the patient.

\section{DISCUSSION}

Results show that guarana, in the studied doses, did not cause enough alterations to characterize any detectable clinical manifestation. Only in the Mosaic test was there a statistical improvement (Guarana Group); however, only one result is not relevant for our study. It is obvious that the statistical difference found in the Digit Symbol test was due to learning, since it was found in all the studied groups. In general, these results are similar to those found in another study on the immediate effects of guarana ${ }^{13}$.

It would seem who the prestige of guarana comes only from its popularity, at least in the studied aspects. Certainly many of the reported effects come from the fact that caffeine is a stimulant and from the "placebo" effect, therefore turning guarana into a tonic beverage. However, it is not totally free from side effects, since four volunteers showed some discomfort, with one not completing the study due to tachycardia, which confirms several reports of people who are sensitive to guarana and present tachycardia (GALDUROZ \& CARLINI, data not published).

At the beginning of this study, we had in mind that the great quantity of tannins ${ }^{25}$ in guarana (our sample had 16 percent) could perhaps act as a "captor" of free-radicals and, therefore, justify some of the effects that are reported by the population. However, one cannot totally disregard that this plant has an adaptive action, since it has already been observed, during in vitro lipid peroxidation, 
that guarana acts as an antioxidant (MATTEI R, et al., data not published).

There are several studies that try to study substances or plants which improve cognition either in normal people or in the mentally ill $^{8,17.20}$ and, unfortunately, guarana has not shown any success.

However, two issues can be brought up to explain these failures: treatment time with guarana was insufficient, although studies on cognition enhancement drugs state that a drug is not efficient when it shows no results after 5 to 6 months of administration ${ }^{23}$. On the other hand, another argument in favor of guarana is that the neuropsychological tests employed were not sensitive enough to detect the expected alterations.
In any case, we do know that this is the first scientific study regarding chronic administration of guarana in human beings.

\section{ACKNOWLEDGMENTS}

Brascap, Guarana Globo S.A., Bertoli AL, Miranda VM, Oliveira R, Sá LC, Aragão F, Nakamura EM, Sartori VA, Seabra MLV, Mouro LC, Andreatini R, Borges MF, Noto AR, and Mattei R.

\section{RESUMO}

A Paulínia cupana (o guaraná) é uma planta da flora brasileira que goza de grande prestigio na medicina popular, entre eles de ser potente estimulante das funçōes cerebrais. Os autores avaliaram os efeitos da administração crônica da guaraná sobre a cogniçâo de voluntảrios idosos normais. Foram estudados 45 voluntários, sendo distribuidos aleatoriamente para um dos três grupos experimentais: Placebo $(n=15)$, Cafeina $(n=15)$ e Guaraná $(n=15)$, em estado duplo-cego. Nāo obteve-se nenhuma mudança significativa na cognição desses voluntários.

\section{REFERENCES}

1. Atkinson C, Shiffrin RM. The control of short-term memory. Scient Amer 1971;225:82-90.

2. Baranov AI. Medical uses of ginseng and related plants in the Soviet Union: recent trends in the Soviet literature. J Ethnopharmacol 1982;6:339-353.

3. Benowitz NL. Clinical pharmacology of caffeine. Ann Rev Med 1990;41:277-288.

4. Carlini EA, Braz S, Tronconi LRP, et al. Efeito hipnótico de medicação homeopática e do placebo: Avaliação pela técnica de "duplo-cego" e "cruzamento." Rev Ass. Med Bras 1987;33:83-8.

5. Colonna A, Faglioni P. The performance of hemispheredamaged patients on spatial intelligence tests. Cortex 1966;2:293-307.
6. Crook TH, Lanabe GJ, Youngjonh JR. Diagnosis and assessment of age-associated memory impairment. Clin Neuropharmacol 1990;13:581-591.

7. Diller L, Erber JT. In: Lezak Md, ed. Neuropsychological Assessment, 2nd ed. New York:Oxford University Press, 1983.

8. Erber JT. In: Lezak Md, ed. Neuropsychological Assessment, 2nd ed. New York:Oxford University Press, 1983.

9. Fitten LJ, Perryman KM, Gross PL, Fine H, Cummins J, Marshall, C. Treatment of Alzheimer's disease with shortand long-term oral THA and lecithin: A double-blind study. Am J Psychiatry 1990;47:239-242.

10. Folstei M, Folstein, SE, McHugh PR. "Mini-Mental State"A practical method for grading the cognitive state of patients for the clinician. J Pyschiat Res 1974;12:189-198.

11. Fulder, $S$. The root of being. Ginseng and the pharmacology of harmany. London:Hutchinson \& Co., 1980. 
12. Fulder, S. The drug builds Russians. New Scientist 1980;87:575-9.

13. Galduróz JCF, Carlini EA. Acute effects of Paulínia cupana (Guaraná) on the cognition of normal volunteers. Revista Paulista de Psiquiatria (in press).

14. Glosser G. In: Lezak Md, ed. Neuropsychological Assessment, 2nd ed. New York:Oxford University Press, 1983.

15. Hafner H, Moschel G, Sartorius N. Mental health in the elderly: A review of the present state of research. Berlin, Heidelberg:Springer-Verlag, 1986.

16. Hennan A. Vida Natural - O guaraná: sua cultura, propriedades, formas de preparação e uso. Global/Ground, 2nd ed., 1986.

17. Hindmarch I, Coleston DM, Kerr JS. Psychopharmacological effects of pyritional in normal volunteers. Neuropsychobiology 1991;24:159-164.

18. Lezak MD. Neuropsychological Assessment. New York:Oxford University Press, 1983.

19. Nazario M. Guaraná - a energia da floresta. Saúde 1989;6:40-51.
20. Patat A, Klein MJ, Surjus A, Hucher M, Granier J. RV 41656 does not reverse the scopolamine-induced cognitive deficit in healthy volunteers. Eur J Clin Pharmacol 1991;41:225231.

21. Pio Corrêa M. Dicionário das plantas úteis do Brasil e das exóticas cultivas. Vol. III. Ed. Ministério da Agricultura (IBDF), 1984.

22. Spielberger CD, Gorsuch RL, Lushene RE. Manual for statetrait anxiety inventory ("self-evaluation questionnaire"). California:Consulting Psychologists Press, 1970.

23. Villardita C, Grioli S, Lomeo C, Cattaneo, Parini, J. Clinical studies with oxiracetam in patients with dementia of Alzheimer type and multi-infarct of mild to moderate degree. Neuropsychobiology 1992;25:24-8.

24. Wechsler DA. A standardized memory scale for clinical use. J Psychol 1945:87-95.

25. Yoshizawa S, Horiuchi T, Fugiki H, Yoshida T, Okuda T, Sigimura T. Antitumor promoting activity of epigallocatechin gallate, the main constituent of "tannin" in green tea. Psytotherapy Res 1987:1:44-7. 